\section{Commentary: Pseudoxanthoma elasticum: An orphan disease with important implications for cardiothoracic surgeons}

\section{Roman Gottardi, MD, MBA, FECTS}

Anderson and colleagues ${ }^{1}$ present an interesting case report on the successful treatment of a patient with pseudoxanthoma elasticum (PXE) who underwent minimally invasive aortic valve replacement for severe aortic stenosis. PXE, also called Grönblad-Strandberg syndrome, is an orphan disease and is characterized by ectopic mineralization and fragmented elastic fibers of the connective tissue of the skin, retina, and vascular walls. ${ }^{2}$ PXE is in most cases initially diagnosed during childhood or adolescence with its characteristic skin lesions; that is, small yellow papules on the nape and the sides of the neck and the flexural areas. Vascular sins of PXE usually become apparent years after the onset of skin and ocular lesions. In patients with PXE, the arterial media and intima are influenced by the dystrophic calcium/phosphate mineralization. The leading clinical manifestation of the arterial wall mineralization is intermittent claudication in upper and lower extremities, but any arterial vessel can be influenced by the characteristic changes.

Cardiothoracic surgeons are used to dealing with patients who have extensive calcifications of the aorta and the aortic valve. What makes patients with PXE so special for treating physicians is the fact that special considerations need to be taken into account regarding postoperative anticoagulation strategies (Figure 1). As the authors correctly describe in their case report, anticoagulation with vitamin $\mathrm{K}$ antagonists should be avoided because

From the Department of Cardiac, Thoracic, and Vascular Surgery, Mediclin Heart Institute, Lahr/Baden, Germany.

Disclosures: The authors reported no conflicts of interest.

The Journal policy requires editors and reviewers to disclose conflicts of interest and to decline handling or reviewing manuscripts for which they may have a conflict of interest. The editors and reviewers of this article have no conflicts of interest

Received for publication July 30, 2021; revisions received July 30, 2021; accepted for publication July 30, 2021; available ahead of print Aug 4, 2021.

Address for reprints: Roman Gottardi, MD, MBA, FECTS, Department of Cardiac,

Thoracic and Vascular Surgery, Mediclin Heart Institute Lahr/Baden, Hohbergweg

2, 77933 Lahr, Germany (E-mail: roman.gottardi@gmail.com).

JTCVS Techniques 2021;9:40-1

2666-2507

Copyright (C) 2021 The Author(s). Published by Elsevier Inc. on behalf of The American Association for Thoracic Surgery. This is an open access article under the CC BY-NC-ND license (http://creativecommons.org/licenses/by-nc-nd/4.0/). https://doi.org/10.1016/j.xjtc.2021.07.022

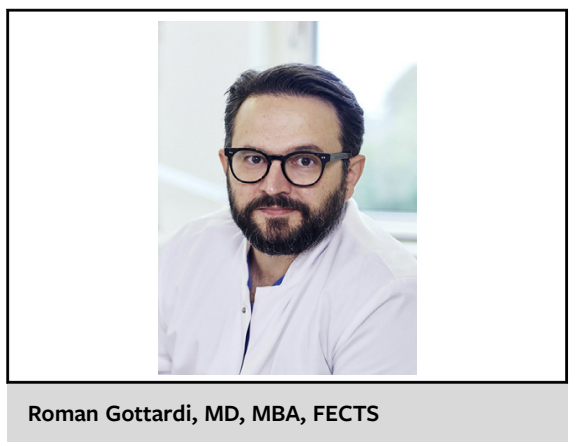

CENTRAL MESSAGE

Pseudoxanthoma elasticum is a rare genetic disease that requires special attention to anticoagulation therapy.

this can lead to a progression and worsening of the underlying disease with an increased risk of mineralization; therefore, warfarin or any other vitamin $\mathrm{K}$ antagonist should not be used in patients with PXE. Patients with PXE have a $15 \%$ risk of hemorrhage of the gastrointestinal or urinary tract compared with a $0.1 \%$ risk in the general population. Clearly, antiplatelet therapy carries a higher risk for bleeding complications in patients with PXE. If the risk of thrombosis outweighs the risk of bleeding, antiplatelet therapy is an option but should be limited to monotherapy. ${ }^{3}$ There are no data available on anti-Xa inhibitors like apixaban or rivaroxaban in patients with PXE, but as in the case described, with a high risk of thromboembolic events it seems justifiable to use anti-Xa inhibitors. ${ }^{4}$ To date, there is no specific therapy for patients with PXE. Because patients with PXE have reduced levels of inorganic pyrophosphate, a powerful inhibitor of ectopic mineralization normalization of plasma levels of inorganic pyrophosphate could prevent further ectopic mineralization and potentially could stabilize the disease. ${ }^{5}$

\section{References}

1. Anderson D, Gustafson J, Tseng EE. Minimally invasive surgical aortic valve replacement in setting of pseudoxanthoma elasticum. J Thorac Cardiovasc Surg Tech. 2021;9:36-9.

2. Germain DP. Pseudoxanthoma elasticum. Orphanet J Rare Dis. 2017;12:85.

3. Baglini R, Sesana M, Capuano C, Danzi GB. Intracoronary ultrasound guided percutaneous coronary angioplasty using a drug eluting stent in a patient with pseudoxanthoma elasticum. Atherosclerosis. 2005;180: $205-7$. 



FIGURE 1. Anticoagulation in patients with pseudoxanthoma elasticum (PXE).

4. Liaqat M, Heymann WR. Anticoagulation in patients with pseudoxanthoma elasticum. Skinmed. 2017;15:319-20.
5. Luo H, Li Q, Cao Y, Uitto J. Therapeutics development for pseudoxanthoma elasticum and related ectopic mineralization disorders: update 2020. J Clin Med. 2020;10:114. 